\title{
Basics of research paper writing and publishing
}

\author{
Michael Derntl \\ RWTH Aachen University \\ Advanced Community Information Systems (ACIS), \\ Lehrstuhl Informatik 5, Ahornstr. 55, \\ 52056 Aachen, Germany \\ Email: derntl@dbis.rwth-aachen.de
}

\begin{abstract}
Publishing research results is an integral part of a researcher's professional life. However, writing is not every researcher's favourite activity, and getting a paper published can be a very tedious and time-consuming process. Fortunately, many of the obstacles along the writing and publishing path can be avoided by following some simple guidelines and practices. This paper presents a synthesis of guidelines found in literature about structuring and writing scientific papers. The paper outlines the process of publishing research papers in journals and conference proceedings, aiming to provide early-stage researchers with a handy introduction to essential issues. The paper takes an interdisciplinary stance by giving examples from technology-enhanced learning research and borrowing from literature in social, natural and computing sciences.
\end{abstract}

Keywords: paper writing; publication process; paper structure; journal publications; conference publications; writing tips; scientific practice.

Reference to this paper should be made as follows: Derntl, M. (2014) 'Basics of research paper writing and publishing', Int. J. Technology Enhanced Learning, Vol. 6, No. 2, pp.105-123.

Biographical notes: Michael Derntl is a Senior Researcher at the Information Systems chair at RWTH Aachen University, Germany. He has conducted and managed R\&D in several publicly funded projects in the area of technologyenhanced learning at University of Vienna and RWTH Aachen University. He holds a $\mathrm{PhD}$ in Information Systems from University of Vienna. He has given seminars and workshops on scientific writing and publishing at the University of Vienna and the Joint European Summer School on Technology Enhanced Learning, respectively.

\section{Introduction}

The dissemination of research results and findings is an integral part of the research process and the career in academia. Researchers write to keep records of their work for themselves, but more importantly for readers and peers who are expecting a standard form, language and style when reading research papers. Writing in a scientific style may be hard in the beginning for novices, but clear communication and concise writing for a scientific audience can be trained (Davis, 1997). 
Robert Day (1983) defines a scientific paper as "a written and published report describing original research results" (p.1). Day claims that scientific papers have to meet certain requirements regarding how the paper was written and the way it is published. He stresses that the process leading to publication is equally important as the content, style and organisation of the published paper. According to this view, a scientific paper must be a valid publication, i.e. it must be published in the right place, like in a peer-reviewed journal or in a top-ranked conference. The publication outlet nowadays heavily relies on the field of research, for instance in computer science, papers in proceedings of some of the top-ranked conferences are equally or even more prestigious than articles in highly ranked journals, while in the natural sciences, conference publications have little to no value in the track record. Regardless of the publication outlet, a validly published scientific paper must contain the "first disclosure of results with sufficient information to enable peers ( $i$ ) to assess observations, (ii) to repeat experiments, and (iii) to evaluate intellectual processes" (Council of Biology Editors, 1968, pp.1-2, as cited in Day, 1983, p.2).

Editors and publishers expect a standard form and structure of submitted papers and published versions for reviewers and readers. The form may vary considerably by type of paper (e.g. a case study is presented in a different form from a survey paper), but the basic building blocks are similar. Some parts of a paper are also relevant for indexing services, which expect title, authors, affiliations, abstract and similar pieces of (meta)information. Dealing with these issues, the first part of this paper (Sections 2-4) focuses on the structural components of scientific papers and basic writing guidelines. Dealing with publishers, editors, peer reviewer's comments, deadlines, submission and style guidelines, and other obstacles on the way to the paper appearing in a printed volume is probably one of the most exhausting tasks in a researcher's life. To shed light on these issues, Section 5 of this paper outlines motivations and avenues to publish research papers.

The main objective of this paper is to serve early-stage researchers with handy introduction to the structural components of scientific papers and the processes that lead to their publication. This paper assumes no explicit disciplinary perspective. It borrows from the literature on paper writing and publishing and gives examples from the social, natural and technical sciences, since the prestige associated with different types of publications varies greatly by discipline. In computer science, for instance, it is possible to make career steps based mostly or exclusively on publications in conference proceedings, which would be unthinkable in most other fields of science. In interdisciplinary research, for instance in technology-enhanced learning, it is therefore essential to be aware of these disciplinary differences and also the commonalities that drive scientific progress and propel personal career development.

\section{Intentions for paper writing}

One may ask why researchers write up what they have been doing or what they are currently working on. Booth et al. (1995) deliver three obvious reasons (pp.8-9): to remember, because once something is forgotten, it cannot be reproduced correctly without having written notice; to understand, as writing about a subject can only be accomplished by approaching the subject in a structured way, which itself leads to better 
understanding thereof; and to gain perspective, as writing includes looking at something from different points of view.

Still the question remains why researchers turn their writing into formal papers. Writing for others is more demanding than writing for oneself, but it can also contribute to obtaining a better understanding of the own ideas and results (Booth et al., 1995). As publications have system-maintaining roles in their respective sciences, additional motivations for researchers to write and publish their research work are (Stock, 2000) are follows:

- scientific communication: O'Connor(1995) points out that this is essential if science is to progress;

- ideal and legal protection of intellectual property;

- gaining reputation;

- thinking in economic measures, 'sale to achieve high prices' may be transformed to 'publish to achieve many citations' (economic theory of science).

Peat et al. (2002) provide a list of rather pragmatic reasons for writing up and publishing research results. Among them are having results that are worth reporting; wanting to progress scientific thought; wanting to reach a broad audience; improving the chance of promotion; and it is unethical to conduct a study and not report the findings.

For many academics, it is actually an implicit or explicit requirement to publish papers. For instance, this is the case for $\mathrm{PhD}$ researchers whose institutions or supervisors demand a certain record of published, peer-reviewed papers, or for researchers whose follow-up contract or salary depends on their publication record.

\section{Structure of scientific papers}

The structure of a research paper comprises three core parts, namely introduction, body and discussion. The progression of the thematic scope of a paper within these parts typically follows a pattern called the 'Hourglass Model' (see Figure 1, light-grey parts; cf. Swales, 1993): The introduction leads the reader from general motivations and a broad subject to a particular research question that is tackled in the body of the paper. The body of the paper stays within a tight thematic scope and describes the research methods and results in detail. Eventually, the discussion part aims to draw general conclusions and present implications from the results. This thematic progression is also reflected in Berry's (1986) claim that a research paper should be circular in argument, i.e. the conclusion should return to the opening, and examine the original purpose in the light of the presented research.

However, there are additional parts of a paper with similar importance. These are title, abstract and references. The extended Hourglass Model, which I chose to call the 'King Model' of paper structure for its visual resemblance of the chess piece, is shown as an extension of the Hourglass Model indicated by the dark-grey parts in Figure 1. The following subsections describe all parts of a paper following the King Model. 
Figure 1 The 'Hourglass Model' (light-grey parts) and the 'King Model', which covers an extended set of parts in a typical paper's structure

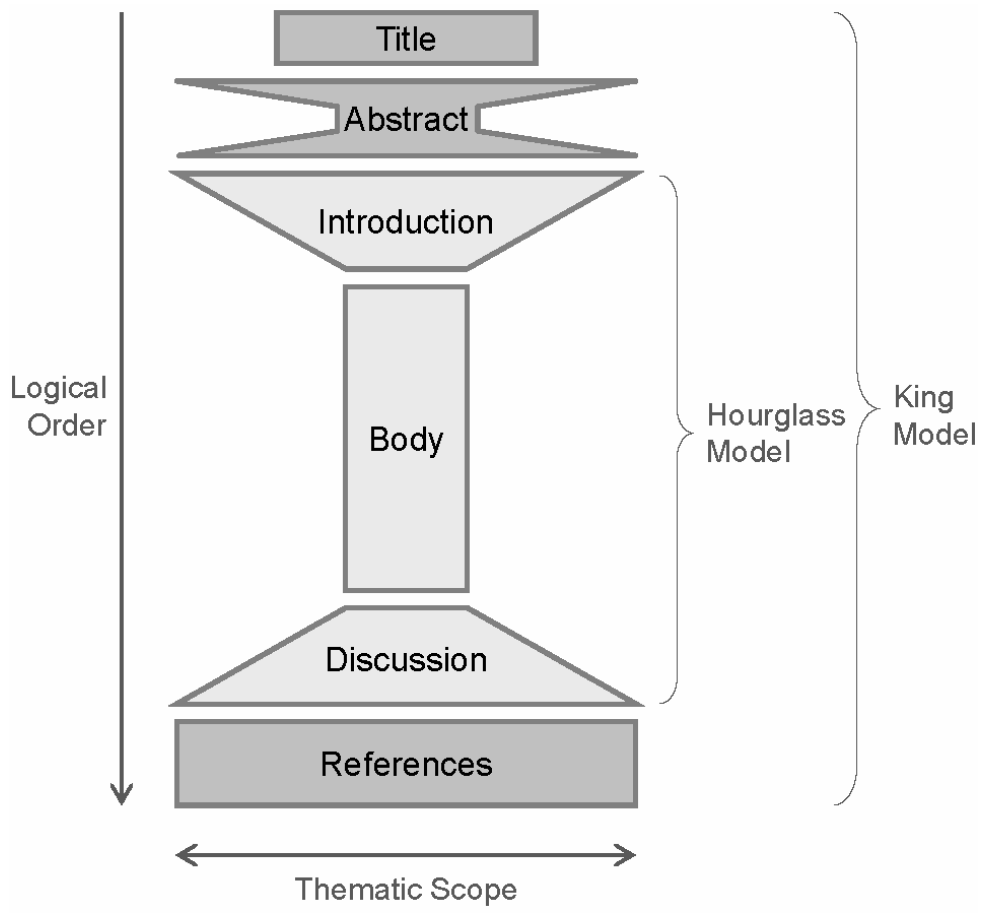

Source: Based on Swales (1993)

\subsection{Title}

The title is the part of a paper that is read the most; it is usually read first and most often, it is the only thing that is read. Electronic indexing services rely heavily on the accuracy of the title to allow users to find papers that are relevant to their research. Day (1983) defines a good title "as the fewest possible words that adequately describe the contents of the paper" (p.9). When the title is too long, it usually contains too many waste words such as 'Investigations on' at the beginning. On the other hand, titles that are too short often use words which are too general. For instance, the title "Writing Reports" does not provide any information on which kind of reports the paper is focusing on. Thus, according to Peat et al. (2002), effective titles

- $\quad$ identify the main issue of the paper;

- $\quad$ begin with the subject of the paper;

- $\quad$ are accurate, unambiguous, specific and complete;

- do not contain abbreviations unless they are well known by the target audience, e.g. HTML or CPU in titles of computer science papers or ADHD in titles of psychology papers;

- $\quad$ attract readers. 
There are different types of title. In Jamali and Nikzad (2011), the authors differentiate descriptive titles, which describe what the paper is about (e.g. 'Investigating the role of academic conferences on shaping the research agenda'); declarative titles, which make a statement about the results presented in the paper (e.g. 'Academic conferences shape the short-term research agenda'); interrogative titles, which pose a question (e.g. 'Do academic conferences shape the research agenda?'); and compound titles, which may combine several of the above separated by colons or question marks (e.g. 'Do academic conferences shape the research agenda? An empirical investigation'). The authors investigated the impact of the title type on the download and citation count of a paper. Interrogative titles have more downloads but fewer cites. Compound titles with colon are longer and have fewer downloads and cites. Long titles tend to get fewer downloads than shorter titles.

Let us examine some examples of titles from published papers and see what types and characteristics they expose:

- 'Educational Technology and Culture: The Influence of Ethnic and Professional Culture on Learners' Technology Acceptance': a compound, mostly descriptive title, which is relatively long with 15 words. Despite its length, it does not reveal the findings of the study.

- 'HT06, tagging paper, taxonomy, Flickr, academic article, to read': an interesting variant of a descriptive title that is self-reflective. The paper is about tagging, published at the Hypertext conference in 2006 (HT06) and it uses a list of tags as its title including a reference to the conference. Due to its unusual style, it will probably stand out in a table of contents and thus attract readers.

- 'A New Framework for Dynamic Adaptations and Actions': a descriptive title that reveals only little about the content of the paper. Moreover, it is fairly unspecific by not clarifying what kinds of adaptations and actions are dealt with. Unless this is clear in the target community, the title should include some declarative pieces (e.g. what characteristics does the framework expose other than that it is 'new'?)

- 'Go To Statement Considered Harmful': a declarative, short title, which will be rather meaningless to non-computer scientists. This is the title of an influential paper published by Edsger Dijkstra in 1968, and the style of the title referring to a common practice that is suboptimal as being 'considered harmful' has since been adopted for many other papers.

\subsection{Abstract}

Basically, an abstract comprises a one-paragraph summary of the whole paper. Abstracts have become increasingly important, as electronic publication databases are the primary means of finding research reports in a certain subject area today (Koopman, 1997). Hence, everything of relevance to potential readers should be in the abstract, everything else not.

According to Day (1983), there are two basic types of abstract:

- An informative abstract extracts everything relevant from the paper, such as research objectives addressed, methods employed in solving the problems, results obtained and conclusions drawn. Such abstracts may serve as a highly aggregated substitute for the full paper. 
- On the other hand, an indicative or descriptive abstract rather describes the content of the paper and may thus serve as an outline of what is presented in the paper. This kind of abstract cannot serve as a substitute for the full text.

A checklist defining relevant parts of an abstract is proposed in Koopman (1997), whereas the author suggests packing each part into one sentence. Note that the thematic scope of an abstract progresses in a similar way as the complete paper following the Hourglass Model:

1 Motivation: Why do we care about the problem and the results?

2 Problem: What problem is the paper trying to solve and what is the scope of the work?

3 Solution: What was done to solve the problem?

4 Results: What is the answer to the problem?

5 Implications: What implications does the answer imply?

Also, there are some things that should not be included in an abstract, i.e. information and conclusions not stated in the paper, references to other literature (although this may vary by journal), the exact title phrase and illustrative elements such as tables and figures (Day, 1983). It is also not beneficial to use the exact phrases that appear later in the introduction. Further useful hints and comments on preparing and writing abstracts are given on various educational and professional websites, such as in Koopman (1997), Hammermeister (2002) and Procter (2002), to mention a few.

An example of an informative abstract that meets all mentioned requirements is given in Table 1 (left-hand side). In contrast, the right-hand side of the table shows an abstract that is lacking a clear description of results and conclusions.

\subsection{Introduction}

The introduction serves the purpose of leading the reader from a general subject area to a particular field of research. Three phases of an introduction can be identified (Swales, 1993):

1 Establish a territory: bring out the importance of the subject and/or make general statements about the subject and/or present an overview on current research on the subject.

2 Establish a niche: oppose an existing assumption or reveal a research gap or formulate a research question or problem or continue a tradition.

3 Occupy the niche: sketch the intent of the own work and/or outline important characteristics of the own work; outline important results; and give a brief outlook on the structure of the paper.

In brief, the introduction should guide the reader to current state of the art in the field and should allow the reader to understand the rest of the paper without referring to previous publications on the topic (Day, 1983). Even though the introduction is the first main 
section in a paper, many researchers write - or at least finish - it rather late in the paper writing process, as at this point the paper structure is complete, the reporting has been done and conclusions have been drawn.

Table 1 Parts of an abstract: two examples

\begin{tabular}{|c|c|c|}
\hline & $\begin{array}{c}\text { Title: 'Paper interfaces for } \\
\text { learning geometry' }\end{array}$ & $\begin{array}{l}\text { Title: 'Unsupervised auto-tagging } \\
\text { for learning object enrichment' }\end{array}$ \\
\hline Motivation & $\begin{array}{l}\text { An online presence is gradually becoming an } \\
\text { essential part of every learning institute. As } \\
\text { such, a large portion of learning material is } \\
\text { becoming available online. }\end{array}$ & $\begin{array}{l}\text { Paper interfaces offer tremendous } \\
\text { possibilities for geometry } \\
\text { education in primary schools. }\end{array}$ \\
\hline Problem & $\begin{array}{l}\text { Incongruently, it is still a challenge for authors } \\
\text { and publishers to guarantee accessibility, support } \\
\text { effective retrieval and the consumption of } \\
\text { learning objects. One reason for this is that non- } \\
\text { annotated learning objects pose a major problem } \\
\text { with respect to their accessibility. Non-annotated } \\
\text { objects not only prevent learners from finding } \\
\text { new information; but also hinder a system's } \\
\text { ability to recommend useful resources. }\end{array}$ & $\begin{array}{l}\text { Existing computer interfaces } \\
\text { designed to learn geometry do not } \\
\text { consider the integration of } \\
\text { conventional school tools, which } \\
\text { form the part of the curriculum. } \\
\text { Moreover, most computer tools } \\
\text { are designed specifically for } \\
\text { individual learning; some propose } \\
\text { group activities, but most } \\
\text { disregard classroom-level } \\
\text { learning, thus impeding their } \\
\text { adoption. }\end{array}$ \\
\hline Solution & $\begin{array}{l}\text { To address this problem, commonly known as } \\
\text { the cold-start problem, we automatically } \\
\text { annotate specific learning resources using a } \\
\text { state-of-the-art automatic tag annotation } \\
\text { method: } \alpha \text {-TaggingLDA, which is based on } \\
\text { the Latent Dirichlet Allocation probabilistic } \\
\text { topic model. We performed a user evaluation } \\
\text { with } 115 \text { participants to measure the usability } \\
\text { and effectiveness of } \alpha \text {-TaggingLDA in a } \\
\text { collaborative learning environment. }\end{array}$ & $\begin{array}{l}\text { We present an augmented reality- } \\
\text { based tabletop system with } \\
\text { interface elements made of paper } \\
\text { that addresses these issues. It } \\
\text { integrates conventional geometry } \\
\text { tools seamlessly into the activity } \\
\text { and it enables group- and } \\
\text { classroom-level learning. In order } \\
\text { to evaluate our system, we } \\
\text { conducted an exploratory user } \\
\text { study based on three learning } \\
\text { activities: classifying } \\
\text { quadrilaterals, discovering the } \\
\text { protractor and describing angles. } \\
\text { We observed how paper interfaces } \\
\text { can be easily adopted into the } \\
\text { traditional classroom practices. }\end{array}$ \\
\hline Results & $\begin{array}{l}\text { The results show that automatically generated } \\
\text { tags were preferred } 35 \% \text { more than the original } \\
\text { authors' annotations. Further, they were } 17.7 \% \\
\text { more relevant in terms of recall for users. }\end{array}$ & - \\
\hline Implications & $\begin{array}{l}\text { The implication of these results is that } \\
\text { automatic tagging can facilitate effective } \\
\text { information access to relevant learning objects. }\end{array}$ & - \\
\hline
\end{tabular}

Sources: Diaz-Aviles et al. (2011) and Bonnard et al. (2012) 


\subsection{Body}

The body of a paper reports on the actual research done to answer the research question or problem identified in the introduction. It should be written as if it were an unfolding discussion, each idea at a time (Dees, 1997). Often, the body comprises several sections and subsections, whereas structure, organisation and content depend heavily on the type of paper, publication outlet, publisher and the creativity of the authors. Some examples are given below.

- In empirical papers, the paper body describes the material and data used for the study, the methodologies applied to answer the research questions and the results obtained. It is very important that the study is described in a way that makes it possible for peers to repeat or to reproduce it (Day, 1983).

- Case study papers describe the application of existing methods, theory or tools. Crucial is the value of the reflections abstracted from the experience and their relevance to other designers or to researchers working on related methods, theories or tools.

- Methodology papers describe a novel method which may be intended for use in research or practical settings (or both), but the paper should be clear about the intended audience.

- Theory papers describe principles, concepts or models on which work in the field (empirical, experience, methodology) is based; authors of theoretical papers are expected to position their ideas within a broad context of related frameworks and theories. Important criteria are the originality or soundness of the analysis provided as well as the relevance of the theoretical content to practice and/or research in the field.

Generally, the body of a paper answers two questions, namely how was the research question addressed (materials, methods) and what was found (results; Davis, 1997; Day, 1983; Peat et al., 2002).

\subsection{Discussion}

Thinking in terms of the Hourglass Model (cf. Figure 1), the discussion part (sometimes presented as 'Discussion', 'Discussion and Conclusion', or simply 'Conclusion') is the counterpart to the introduction since this part should lead the reader from narrow and/or very specific results to more general conclusions. Generally, this part includes (cf. Day, 1983; Swales, 1993) the following:

- A presentation of background information as well as recapitulation of the research aims of the study.

- A brief summary of the results, whereas the focus lies on discussing and not recapitulating the results.

- A comparison of results with previously published studies.

- Conclusions or hypotheses drawn from the results, with summary of evidence for each conclusion.

- Proposed follow-up research questions and outlook on further work. 
According to Day (1983), something that is often not adequately dealt with is a discussion about the significance and implications of the results; a good place for doing so is the end of the discussion part.

\subsection{References}

Embedding the own work in related literature is one of the essential parts of research writing. This is achieved by citing related work within the text and by listing all cited references at the end of the paper. Different publishers require different formats or styles for citing a paper in the text and for listing references. The most commonly used referencing systems are variations of the following (cf. Day, 1983):

- Name and year system. References are cited by their respective authors and the year of publication, e.g. 'Chuck and Norris (2003) define ...'. This system is very convenient for authors, as the citation does not have to be changed when adding or removing references from the list. The fact that sentences become hard to read when subsequently citing many references in one single parenthesis this way is one negative aspect for readers.

- Alphabet-number system. This system lists the references in alphabetical order and cites them by their respective number in parentheses or (square) brackets, e.g. ' $A s$ reported in [4], ...'. This system is relatively convenient for readers, as it does not break the flow of words while reading a sentence with many citations. On the other hand, the author has to keep an eye on the references cited in the text as their numbers may change when the reference list is updated.

- Citation order system. This system is similar to the alphabet-number system with one major difference: the reference list is not sorted alphabetically, but in the order of appearance (citation by number) in the text.

Variations of the referencing systems mentioned above are used in most of the common style guides, for instance American Psychological Association (APA) style (American Psychological Association, 2003), Chicago style (The University of Chicago, 2010), Council of Biology Editors (CBE) style and Modern Language Association (MLA) style (Gibaldi, 1995). In computer science, the most widely used styles are variations of the number system, e.g. the style used by Springer Verlag in the Lecture Notes series, the style used by the Association for Computing Machinery (ACM) Press and the style guides issued by the IEEE Computer Society for most of their publications. In general, the citation system used depends on the scientific discipline (e.g. psychologists mainly use APA style), on the publisher (different publishers may require to use different referencing styles even in the same field) and on the publication outlet. Authors have no other choice than adhering to the style required by publishers.

Regardless of the citation style, there are two basic rules for the list of references: (1) every cited source must be listed and (2) every listed source must be cited.

\section{Writing for publication}

Papers must be written for a specific audience. This is particularly important for doctoral students trying to publish parts of their thesis. A scientific paper is written for the editor 
and audience of the intended publication outlet, while the key audience of the thesis is the supervisor (Berry, 1986). Hence, the place of publication should be selected prior to writing the paper, and chapters extracted from theses have to be reconsidered accordingly (Davis, 1997). Related to parts of theses being published as research papers; Berry (1986, pp.105-108), notes that

- "Theses are written for supervisors who have to be convinced that one has really done work. No corners are cut. Space is no object [...] Nothing of this applies to learned journals."

- The professional public does not need to have everything spelled out, instead it "would like to learn something it did not already know, expressed in succinct prose, the points made in an agile and alert manner."

- Two of the most important rules are 'target the journal' (i.e. its editor and audience) and 'research the market' to get to know available and appropriate journals in the field.

- After having chosen the preferred journal for publication, all efforts should be directed to place the paper in that specific journal. It is helpful to study papers previously published in that journal with respect to paper organisation, presentation and writing style.

According to O'Connor (1995), several steps have to be taken to prepare a research paper for professional publication. First, the researchers have to ask themselves some preliminary questions to make sure that the studies are designed to answer precisely the research question under examination, that the experiments meet accepted standards and that the process of keeping records of the research work is agreed upon in the target community. Subsequently, the research work has to be assessed constantly in order to be able to decide whether the work is suitable for submission (speaking to colleagues and writing while work is in progress may turn out to be very helpful in this respect). A paper that "records significant experimental, theoretical or observational extensions of knowledge, or advances in the practical application of known principles" is worth publishing (O’Connor 1995).

Even if the work reported on is considered worth publishing, a major prerequisite for a paper to pass a rigorous peer review process (cf. Section 5.1) prior to publication is a clean, concise and coherent writing style (cf. Section 4), as well as thorough organisation and elaboration of the statement unfolding in the paper. To achieve this, many revisions may be necessary, as Davis' (1997) proposed plan for paper writing shows (Figure 2).

There are many sets of writing tips available from different authors. Two sets of frequently stated tips or rules are presented here. Davis (1997) gives the following set of rules for technical and scientific writing:

- If it can be interpreted in more than one way, it is wrong.

- Know your audience, know your subject, know your purpose.

- If you cannot find a reason to put a comma in, leave it out.

- Keep your writing clear, concise and correct.

- If it works, do it. 
Figure 2 Plan for preparing and writing a paper for publication

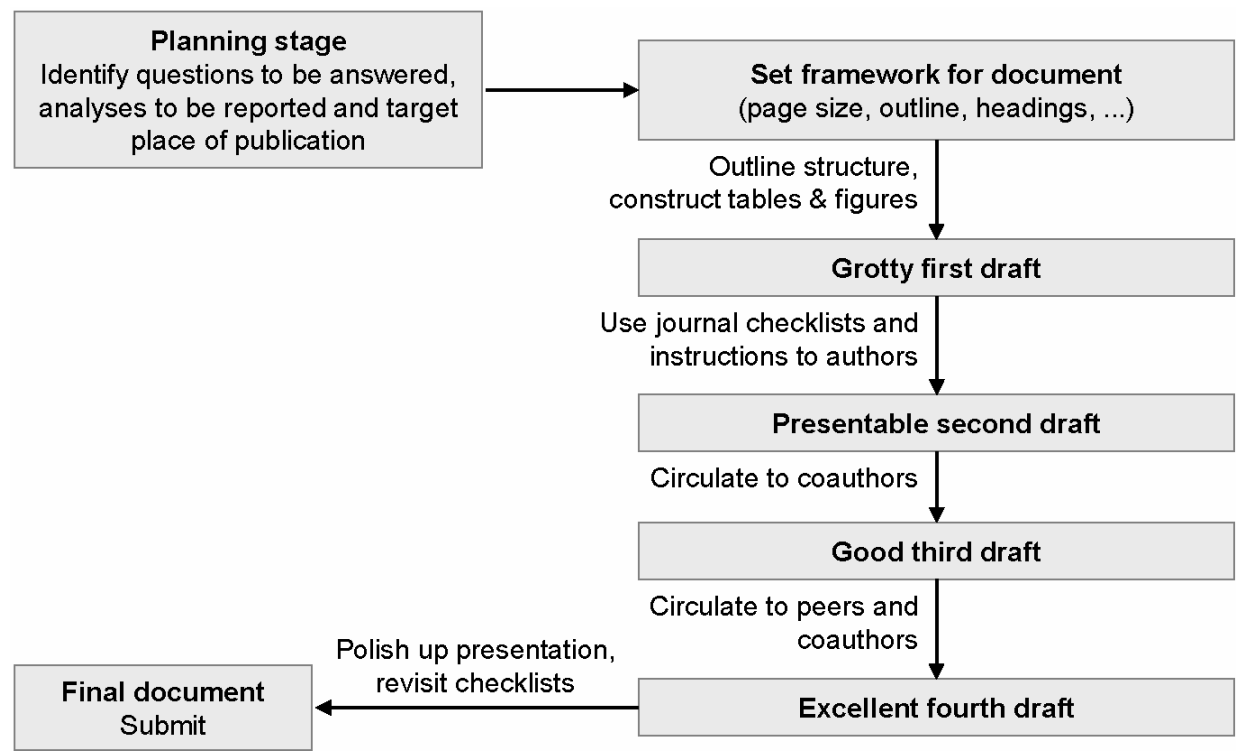

Source: Adapted from Davis (1997)

O'Connor (1995) states the following principles for solving problems of writing style: Be simple and concise.

- Make sure the meaning of every word.

- Use verbs instead of abstract nouns.

- Break up noun clusters and 'stacked modifiers' (i.e. strings of adjectives and nouns, with no clue about which modifies which).

Additionally, it should be mentioned that plagiarism - i.e. using the ideas of someone else without acknowledging the source of information - is considered a serious offence in the scientific community and must therefore be avoided. Credit must be given when using another person's ideas, opinion, theory (also quotations or paraphrases thereof) or information that are not common knowledge

\section{Publishing scientific papers}

When the paper writing is finished and the authors consider the paper to be worth publishing, the next step is to submit it for publication (e.g. to a conference, a journal or a book editor). Essentially, there are two obstacles to publication: the editors and the reviewers. The following sections cover the scientific community's way of assuring scientific quality of published papers and the central stages of the editing, reviewing and publishing process. The selective focus here is on journal articles and conference papers, since in most disciplines - particularly those with relevance for technology-enhanced learning - either (or both) of these publications is what gets researchers promoted. 


\subsection{Scientific quality management}

Peer review is the main mechanism of scientific quality management. Submitted papers are reviewed by peers of the authors in the respective field's scientific community prior to publication; hence, this process is referred to as peer review. It was conceived to ensure publishable quality of research papers (Day, 1983). Some argue that it should continue to do so in the future (Pullinger, 1996), while others are sceptical. For most publication media, the review process is quite similar, with some distinguishing differences. These concern mainly the roles of people involved and the outcome of the process. Common to serious peer reviewing practices is the fact that authors do not know the identity of their reviewers (blind review); depending on the editorial policy, it is also common practice that reviewers should not know the name(s) of the author(s) of the paper (double-blind review).

\subsection{Journal publications}

A journal paper reports on a finished piece of research or some significant achievement or discovery in a certain field of science.

\subsubsection{Roles involved}

The main roles (except authors) involved in the journal editing and publishing process and their responsibilities are as follows (cf. Davis, 1997; Day, 1983; Peat et al., 2002; Yuksel, 2003; National Institute for Regional and Spatial Analysis, 2003; Cormode, 2013):

Reviewer. Each journal has an editorial board that includes a number of reviewers who are responsible for reviewing submitted manuscripts assigned to them by an editor (see below). Having reviewed a paper, each reviewer independently advises the editor whether to accept or reject the paper. It is common practice that editors assign external reviewers to submissions, for example, when the reviewers of the editorial board do not have appropriate expertise to make constructive comments on a particular paper.

Editor-in-chief. The most important function of an editor-in-chief (can also be a group of persons) is to make the final decision whether to accept or reject a submitted paper. Typically, they base their decisions on recommendations from reviewers or associates (see below). If there is agreement in the recommendations on acceptance or rejection, the editor's life will be easy. It becomes difficult only when there is significant disagreement in the recommendations. In such a case, the editor may make a final decision based on the own opinion or after consulting additional reviewers. Typically, an editor-in-chief is assisted by several associate editors (Cormode, 2013).

Associate editor. In case a journal has a board of associate editors, then for each submission an associate editor is assigned as an intermediary between the authors, the reviewers and the editor-in-chief. Associate editors handle the communication with the corresponding authors and they control the reviewing process, including the selection of reviewers and processing of revisions. Based on the reviewers' recommendations, they make a recommendation to the editor whether to accept or reject a submitted manuscript. Depending on the journal, associate editors sometimes represent geographical regions (see e.g. the role of 'Associate Editor Africa' in IJTEL) or thematic areas covered by the journals. Editors-in-chief usually follow the recommendations of their associate editors, although this is not a rule (Cormode, 2013). 
Managing editor. Many journals have managing editors, in particular those with a large number of submissions or frequent issues. Their job is to relieve the editor-in-chief from administrative and other day-to-day tasks in producing a journal (National Institute for Regional and Spatial Analysis, 2003), e.g. coping with publishers. Generally, the difference between editors and managing editors is that the review process (dealing with the author and reviewers) is mostly within the realm of the editors, whereas postacceptance issues are then taken care of by managing editors (Day, 1983).

Publisher. Publishers print accepted papers in (periodical) journal issues. Most journals appear quarterly, but there are also journals which appear in shorter or longer intervals. After the publisher has received the final version of an accepted paper, the paper is prepared for printing. A preview of the typeset paper to be published is then sent to authors, who check the so-called 'page proofs' for any errors that survived the editing and typesetting stages. This process is called proof reading, and it is typically not allowed to make any modifications to the paper other than correcting errors introduced during typesetting; after the author is finished with proof reading, the paper is finally ready to go to print.

Most journals offer the scientific community the possibility of publishing special issues. A special issue is often proposed by senior researchers who have extensive knowledge in the field and access to a network of expert peers in a specialised field of relevance to the journal's theme. In such a case, the persons who propose the special issue take on the role of guest editors and may provide their own special issue editorial board. For instance, conference chairs might invite authors of papers presented at their conference with outstanding peer review scores to submit extended versions to a special issue of a journal related to the conference theme.

\subsubsection{Publication process}

A simplified view of important stages and roles in the publishing process of journal papers is given in the activity diagram in Figure 3. The vertical swim lanes separate the areas of responsibility of the main actors in the process. Note that for simplicity all editorial roles are subsumed under one swim lane.

The first step is to be taken by the author. After choosing an appropriate journal for submission, the author has to submit the paper according to the instructions issued by the journal editor. Most journals today offer the opportunity to submit the paper via the journal's web site or a submission management system. At this stage, it is very important that the author follows the instructions, because submitted papers that do not adhere to (parts of) the instructions can be rejected without taking into account the paper's actual content. Some common authors' mistakes at this stage include:

- not adhering to the journal's paper formatting and layout guidelines (e.g. using the wrong font size, line spacing, page numbering, referencing style, figure and table placement and visual guidelines);

- $\quad$ exceeding maximum paper length (word count, page count);

- the paper's thematic focus not being within the scope of the journal's subject areas.

If any of the above is evident when the editor does the preliminary review, the paper is likely to be immediately rejected regardless of its scientific contribution and quality. On 
the other hand, if these conditions are met ('proper paper on a proper subject'; Day, 1983), the paper will be considered for publication. The submitting author is notified of either one of these decisions.

Figure 3 Simplified activity diagram of the process of publishing a paper in a journal

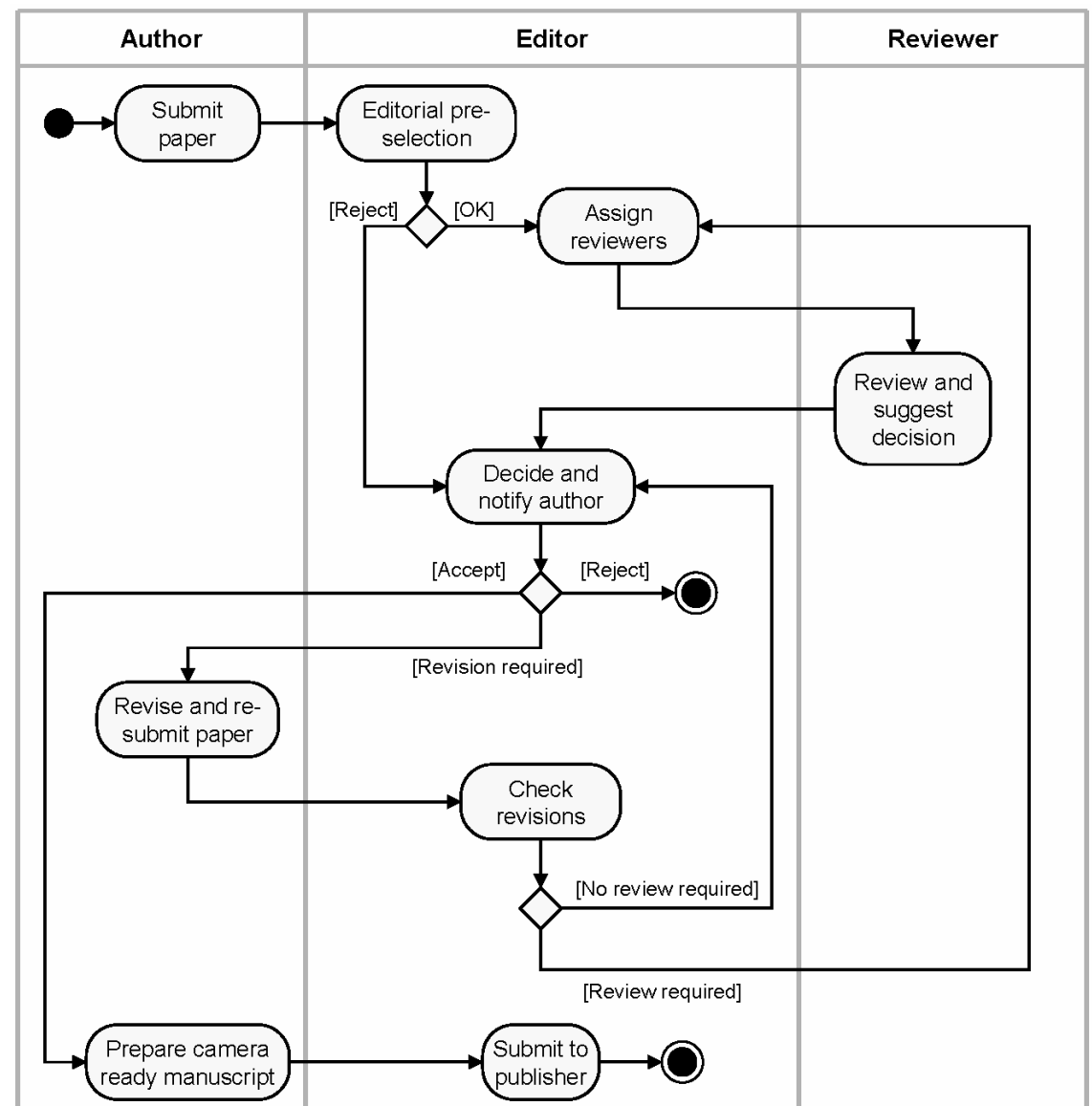

The next step the editor takes is to select reviewers for peer reviewing the paper. The number of reviewers involved in the review process may vary from journal to journal, but usually the editor forwards the paper to at least three reviewers who are experts in the topic that is covered by the paper. Besides making comments and suggestions for improvements to the authors, reviewers generally support the editor in making a decision by providing information on the following general issues, which may vary in importance among different journals (compiled from Davis, 1997; Day, 1983; Peat et al., 2002; Dees, 1997; Yuksel, 2003; Choi, 2002 and Association for Computing Machinery, 2003):

- thematic relevance to the journal's scope of subjects;

- significance of contribution (does the paper contribute new findings to the body of knowledge in the field?); 
- $\quad$ originality of the work (is similar research already published elsewhere?);

- $\quad$ coverage of relevant literature (did the authors report related work?).

Focusing more on the writing style of the paper, the following aspects are relevant to reviewers and might influence their recommended decision:

- clarity of writing: readability, organisation, conciseness and technical quality of the paper;

- $\quad$ appropriate title and abstract;

- $\quad$ appropriate use of well-designed (cf. Day, 1983) figures and tables;

- $\quad$ sound conclusion and discussion;

- length of the paper relative to its usefulness.

Also increasing the likelihood of acceptance are the following characteristics of submitted papers (Yuksel, 2003):

- $\quad$ strong reputation of the author;

- $\quad$ successful test of the proposed theory;

- different content from that usually published in the journal.

When the assigned reviewers have finished reviewing and commenting the paper, the editor collects their recommendations and makes a decision which is sent to the corresponding author, who is indicated in the submitted manuscript. Generally, the notification by the editor will carry one of the following messages (O'Connor, 1995; Day, 1983; Peat et al., 2002):

Accept. The paper is accepted as it was submitted. The paper will be published in one of the journal's forthcoming issues (for details on the printing process and on how to deal with printers, refer to O'Connor, 1995; Day, 1983; Peat et al., 2002). This outcome is very unlikely upon initial submission. Only in very rare cases will the paper be accepted right away. It is more likely that the paper has to be revised.

Revision. The editor requests a revision of (certain parts of) the paper. The authors have to modify the paper according to the suggestions and comments of the reviewers and the editor in order to be further considered for publication. After revising the paper accordingly, the author may submit the revised manuscript to the editor. This typically requires the authors to enclose a letter to the editor where they outline in detail how the reviewer and editorial comments were addressed in the revised version. After receiving the revised version, the editor either makes an accept/reject recommendation or, if required, forwards the paper for another round of reviewing, which usually involves those reviewers who were most critical about the original submission.

Reject. The editor does not see any chance for the paper to be published in the journal. This is the most frequent outcome of the review process of a journal. The editor usually encloses the reviewer comments. Typically, one or more reviewers

- $\quad$ had serious objections to one of the preconditions relevant to reviewers mentioned above;

- found the paper to be out of the journal's scope, lacking relevance or significance; 
- found fundamental flaws in the paper's argument, data or methodology;

- did not see any improvement with regard to previous submissions of the same paper.

If a revision is required and the author feels unable to comply with the editor's recommendations, the author may either inform the editor about the disagreement or, alternatively, the paper may be sent to another appropriate journal in the field. The same applies to rejected papers.

\subsection{Conference publications}

The review system at scientific conferences is quite similar to the journal paper review system, at least in computer science. Nevertheless, there are some differences in the publishing process, which are explained in this section. Generally, papers published in conference proceedings do not have a reputation as high as journal papers. This is particularly true for the natural and social sciences. However, in computer science, there are numerous conferences with journal-equivalent status (Bundy et al., 1989).

While the vast majority of conferences are part of a series taking place annually, some are held biennially. Several months before the conference date, the conference chairs issue a call for papers (often referred to as 'CFP' in both written and oral communications) to invite authors to submit papers to be published in the conference proceedings and to be presented at the conference venue. The CFP, which can normally be downloaded from the conference website, comprises the following information:

Title, acronym and venue: for example, Eighth European Conference on Technology Enhanced Learning (EC-TEL 2013), Paphos, Cyprus.

General information/theme: this section can be found on most CFPs describing the scope or special theme of the conference, i.e. putting the main topic of the conference in the light of current developments.

Topics of interest: encloses a list of topics of particular interest for the respective conference's subject area. During the submission process in the conference management system, the author usually has to select a subset of the topics that best fit the submission. This selection is mostly relevant for assigning peer reviewers, who also select a subset of the conference topics as their area of expertise.

Submission guidelines: most CFPs comprise a section where general guidelines for submissions are communicated to the authors. Additionally, if the conference proceedings are published by a well-established publisher, the publisher is also mentioned in the CFP.

Deadlines: this section lists a number of deadlines to be met by authors. Typically, these include at least:

- Submission deadline: this is the deadline for submitting the complete paper. There are also some conferences that initially require an extended abstract for various reasons (e.g. pre-selection or paper bidding by the programme committee) and then a full paper submission. Most submission deadlines are firm, whereas failure to meet the deadline results irreversibly in not being considered for presentation and/or publication. Since conferences take place in different time zones, the exact submission deadline has to be taken into account by the authors. Since most conferences are annual events, researchers in the community know well in advance when paper will be due for submission. 
- Notification date: this is the date when the author is notified of acceptance or rejection. The notification date given is often not very accurate, as the programme committee cannot anticipate the number of submissions, to mention one reason; also, the peer reviewers often fail to submit their reviews on time. Thus, the review process may take longer than expected. Conferences that use peer review to decide whether a submission should be accepted or not typically emit one of only two messages to each submitting author at the notification date:

- Accept: the paper has been accepted and will be published in the conference proceedings. However, reviewers may have suggested minor modifications to be incorporated in the published paper. Usually, acceptance letters (or mails) sent by organisers include the invitation (typically the obligation) to orally present the paper at the conference. This is a very good opportunity to receive immediate feedback in discussions with peers after the presentation.

- Reject: the paper was rejected and will not be published in the conference proceedings. Most reviewers supply valuable comments to authors on how to improve the rejected paper. Unlike journals, most conferences do not consider the option of asking authors for revision. Papers are normally either accepted or rejected right away.

Some conferences implement a rebuttal process, which allows authors to respond to the reviews before a final decision is made. The reviewers may then elect to change their reviews based on the arguments brought forth by authors during the rebuttal period. This can go either way, i.e. result in lower or higher scores.

Depending on the reputation of the conference and the response to the call for papers, the acceptance rate will vary significantly among different conferences. Most serious conferences disclose the acceptance rate in the preface to the proceedings and/or on their website. The top conferences in computer science usually have an acceptance rate of $10-15 \%$ or lower. Most other conferences with a good reputation will typically accept no more than one quarter of the submissions.

- Camera-ready paper deadline: in case of acceptance, this is the submission deadline for 'camera-ready' papers, i.e. final versions to be included in the conference proceedings. At some conferences, failure to meet this deadline may result in the accepted paper not being included in the conference proceedings.

As with journals, it is vital to meet all deadlines and to comply with all guidelines (such as paper formatting instructions). See Figure 4 for an example of the 'important dates' section in the website of the Eighth European Conference on Technology Enhanced Learning, EC-TEL 2013. Note that in this example the submission deadline was extended once. Such extensions of the submission deadline are common, yet not a rule.

Other information: Other information of interest, e.g. call for workshops to be colocated with the conference, tutorials, panel discussion proposals, demonstrations and information on sponsors, publisher, invited speakers. 
Figure 4 Deadlines of the Eighth European Conference on Technology Enhanced Learning, EC-TEL 2013

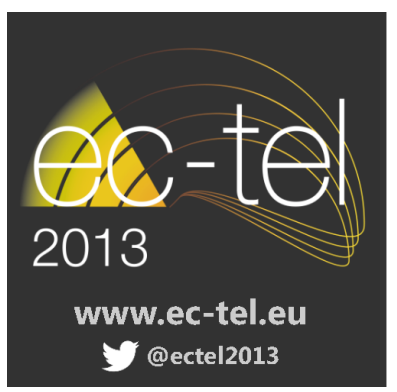

IMPORTANT DATES

(all deadlines are 23:59 CET)

- Abstract submission (papers, posters, demos) 25 March 2013

- Full submission (papers, posters, demos) extended: 9 April 2013

- Notification of acceptance

9 June 2013

- Camera ready versions

28 June 2013

- Room reservation for project meetings deadline $\quad 15$ June 2013

- Workshop proposals due 2 April 2013

- Workshop notifications 30 April 2013

- Workshops

- Project meetings

$17,18,21$ September 2013

- Main conference

Source: http://ectel2013.cs.ucy.ac.cy

\section{Concluding remarks}

The objective of this paper was to give an introduction to basic issues of writing and organising scientific papers as well as on the process of getting a research paper published in a journal or in conference proceedings. We laid out different intentions for writing up research results in a scientific paper. We found that there are intentions that concern the individual (e.g. propelling the own career) and intentions that concern a broader public (e.g. propelling scientific discovery). We discussed in detail the structural parts of a typical scientific paper including title, abstract, body, discussion and references. It was argued that getting the structure and the writing right can be trained based on good examples and basic advice. We presented aspects that distinguish writing for publication from writing other pieces of text like PhD theses. Last but not least, we discussed roles and steps involved in the publication process in journals and conferences.

Technology-enhanced learning is a young and interdisciplinary research area. Hence, the craft of writing and publishing papers in technology-enhanced learning conferences and journals is less mature than in established disciplines from the social and natural sciences. However, covering all these disciplinary facets in detail is beyond the scope of this paper. The paper therefore aimed to provide early-stage researchers with an introductory guide to this complex matter, raising awareness of the fact that very simple rules and guidelines might have a lasting impact on the personal career and science at large.

\section{References}

American Psychological Association (2003) APA Style. Available online at: http://www.apastyle. org/pubmanual.html.

Association for Computing Machinery (2003) Transactions on database systems referee informations. Available online at: http://www.acm.org/tods/Referees.html.

Berry, R. (1986) How to Write a Research Paper, Pergamon Press, Oxford.

Bonnard, Q., Verma, H., Kaplan, F. and Dillenbourg, P. (2012) 'Paper interfaces for learning geometry', in Ravenscroft, A., Lindstaedt, S., Kloos, C. and Hernández-Leo, D. (Eds): 21st Century Learning for 21st Century Skills, LNCS, Vol. 7563, pp.37-50, Springer, Berlin/ Heidelberg. 
Booth, W.C., Colomb, G.G. and Williams, J.M. (1995) The Craft of Research, University of Chicago Press, Chicago, IL.

Bundy, A. du Boulay, B., Howe, J. and Plotkin, G. (1989) The researcher's Bible. Available online at: http://www.cs.duke.edu/ chase/cps300/resbible.pdf.

Choi, K. (2002) How to publish in top journals. Available online at: http://www.roie.org/how.htm.

Cormode, G. (2013) 'What does an associate editor actually do?' SIGMOD Record, Vol. 42, No. 2, pp.52-58.

Council of Biology Editors (1968) Proposed Definition of a Primary Publication, Newsletter, Council of Biology Editors, Wheat Ridge, CO.

Davis, M. (1997), Scientific Papers and Presentations, Academic Press, San Diego, CA.

Day, R.A. (1983) How to Write and Publish a Scientific Paper, ISI Press, Philadelphia, PA.

Dees, R. (1997) Writing the Modern Research Paper, Allyn \& Bacon, Boston, MA.

Diaz-Aviles, E., Fisichella, M., Kawase, R., Nejdl, W. and Stewart, A. (2011) 'Unsupervised autotagging for learning object enrichment', in Kloos, C., Gillet, D., Crespo García, R.M., Wild, F. and Wolpers, M. (Eds): Towards Ubiquitous Learning, LNCS, Vol. 6964, pp.83-96, Springer, Berlin/Heidelberg.

Gibaldi, J. (1995) MLA Handbook for Writers of Research Papers, The Modern Language Association of America, New York.

Hammermeister, S. (2002) How to write an abstract/prospectus, Writing Center, University of Nevada, LA. Available online at: http://writingcenter.unlv.edu/writing/abstract.html.

Jamali, H. and Nikzad, N. (2011) 'Article title type and its relation with the number of downloads and citations', Scientometrics, Vol. 88, pp.653-661.

Koopman, P. (1997) How to write an abstract, Electrical \& Computer Engineering. Available online at: http://www.ece.cmu.edu/ koopman/essays/abstract.html.

National Institute for Regional and Spatial Analysis (2003) Questions editors are often asked. Available online at: http://www.nuim.ie/nirsa/geo-pub/geo-editors.html.

O’Connor, M. (1995) Writing Successfully in Science, Chapman \& Hall, London.

Peat, J., Elliott, E., Baur, L. and Keena, V. (2002) Scientific Writing: Easy When You Know How, BMJ Books, London.

Procter, M. (2002) The abstract. Available online at: http://www.writing.utoronto.ca/advice/ specific-types-of-writing/abstract.

Pullinger, D.J. (1996) 'Economics and organisation of primary scientific publication', Joint ICSU Press/UNESCO Expert Conference on Electronic Publishing in Science, 19-23 February, Paris, France, pp.139-148.

Stock, W.G. (2000) 'Was ist eine Publikation? Zum Problem der Einheitenbildung in der Wissenschaftsforschung', in Fuchs-Kittowski, K., Laitko, H., Parthey, H. and UmstÃatter, W. (Eds): Wissenschaftsforschung Jahrbuch 1998, Verlag für Wissenschaftsforschung, Berlin, pp.239-282 (in German).

Swales, J.M. (1993) Genre Analysis: English in Academic and Research Settings, Cambridge University Press, Cambridge.

The University of Chicago (2010) The Chicago Manual of Style. Available online at: http://www. chicagomanualofstyle.org/.

Yuksel, A. (2003) 'Writing publishable papers', Tourism Management, Vol. 24, No. 4, pp.437-446. 